\title{
Embryonic endocrine pancreas and mature $\beta$ cells acquire $\alpha$ and PP cell phenotypes upon Arx misexpression
}

\author{
Patrick Collombat, ${ }^{1}$ Jacob Hecksher-Sørensen, ${ }^{2}$ Jens Krull, ${ }^{1}$ Joachim Berger, ${ }^{3}$ Dietmar Riedel, ${ }^{4}$ \\ Pedro L. Herrera, ${ }^{5}$ Palle Serup, ${ }^{2}$ and Ahmed Mansouri ${ }^{1}$

\begin{abstract}
'Department of Molecular Cell Biology, Max Planck Institute for Biophysical Chemistry, Göttingen, Germany. ${ }^{2}$ Department of Developmental Biology, Hagedorn Research Institute, Gentofte, Denmark. ${ }^{3}$ Victor Chang Cardiac Research Institute, Darlinghurst, New South Wales, Australia. ${ }^{4}$ Electron Microscopy Department, Max Planck Institute for Biophysical Chemistry, Göttingen, Germany.

${ }^{5}$ Department of Genetic Medicine and Development, University of Geneva Medical School, Geneva, Switzerland.
\end{abstract}

\begin{abstract}
Aristaless-related homeobox (Arx) was recently demonstrated to be involved in pancreatic $\alpha$ cell fate specification while simultaneously repressing the $\beta$ and $\delta$ cell lineages. To establish whether Arx is not only necessary, but also sufficient to instruct the $\alpha$ cell fate in endocrine progenitors, we used a gain-of-function approach to generate mice conditionally misexpressing this factor. Mice with forced Arx expression in the embryonic pancreas or in developing islet cells developed a dramatic hyperglycemia and eventually died. Further analysis demonstrated a drastic loss of $\beta$ and $\delta$ cells. Concurrently, a remarkable increase in the number of cells displaying $\alpha$ cell or, strikingly, pancreatic polypeptide (PP) cell features was observed. Notably, the ectopic expression of $A r x$ induced in embryonic or adult $\beta$ cells led to a loss of the $\beta$ cell phenotype and a concomitant increase in a number of cells with $\alpha$ or PP cell characteristics. Combining quantitative real-time PCR and lineage-tracing experiments, we demonstrate that, in adult mice, the misexpression of Arx, rather than its overexpression, promotes a conversion of $\beta$ cells into glucagon- or PP-producing cells in vivo. These results provide important insights into the complex mechanisms underlying proper pancreatic endocrine cell allocation and cell identity acquisition.
\end{abstract}

\section{Introduction}

The pancreas plays a key role in maintaining nutritional homeostasis, through the synthesis and secretion of enzymes and hormones. The mammalian pancreas consists of 3 tissue types: acinar, ductal, and endocrine. The exocrine pancreas is composed of acinar cells secreting digestive enzymes, which are emptied into the pancreatic duct, an intricate network of tubules composed of epithelial duct cells. Endocrine cells are organized in islets of Langerhans comprising 5 cell types, $\alpha, \beta, \delta$, $\varepsilon$, and PP cells, which produce the hormones glucagon, insulin, somatostatin, ghrelin, and pancreatic polypeptide (PP), respectively. Insulin and glucagon act antagonistically to regulate glucose levels, whereas somatostatin and PP control the production of additional hormones and enzymes (1-3). The function of ghrelin is unclear $(4,5)$. Pancreas morphogenesis begins approximately at E9.5 with the emergence of 2 evaginations of the primitive gut endoderm at the foregut/ midgut junction. These protrusions, or pancreatic buds, further develop, rotate toward each other, and eventually merge, thereby giving rise to the pancreas (6).

Concurrently with pancreas development, the formation of the endocrine tissue is initiated at E9.5, resulting in the emergence of early glucagon-producing cells (7-9). In addition, a subset of these cells initiate insulin and sometimes PYY expression within the next 24 hours (8). At E14.5, the "secondary transition" (10)

Nonstandard abbreviations used: Arx, Aristaless-related homeobox; cArxOE (mouse), transgenic mouse capable of conditionally misexpressing the Arx gene; IndP$\mathrm{dx} 1 \mathrm{Cre}$, inducible Pdx1Cre; Ngn3, Neurogenin3; PP, pancreatic polypeptide. Conflict of interest: The authors have declared that no conflict of interest exists. Citation for this article: J. Clin. Invest. 117:961-970 (2007). doi:10.1172/JCI29115. results in the development of numerous mature insulin- and glucagon-expressing cells, followed the next day by the appearance of the first somatostatin-producing $\delta$ cells. Finally, shortly before birth, PP cells differentiate and endocrine cells begin to form wellorganized islets of Langerhans that will be further matured for 2-3 weeks following birth.

Recent findings have revealed a number of genetic determinants underlying endocrine cell genesis. Pancreatic progenitors are first committed toward the pancreatic lineage through the action of several transcription factors, including the homeodomain-containing factor Pdx1 (11-15). Subsequently, the endocrine differentiation program is initiated though the activation of the basic helix-loop-helix factor Neurogenin3 (Ngn3), in the mouse pancreatic epithelium (16-20). Accordingly, mice deficient in Ngn3 fail to generate any endocrine cells (21), whereas the misexpression of $N g n 3$ under the control of the $P d x 1$ promoter results in the differentiation of most pancreatic cells into endocrine cells (16, 19). Subsequently, a complex network of transcription factors is activated to progressively and differentially specify the endocrine subtype lineages. These include the homeodomain-containing proteins Nkx2.2, Nkx6.1, Arx, Pax4, and Pdx1 (22-26). Once cell fate has been established, additional transcription factors such as Isl1, Pax6, MafA, MafB, and Pdx1 act to maintain the phenotype of specified islet cells $(11,13,27-32)$.

The key role exerted by Arx and Pax4 in the allocation of the 4 classical endocrine cell fates was recently unraveled. Hence, in the pancreata of mice carrying a targeted mutation of the Arx gene, a loss of mature $\alpha$ cells and a proportional increase in the number of $\beta$ and $\delta$ cells is detected, so that the total islet cell content remains unaltered (24). Such phenotypic changes are opposite to those 


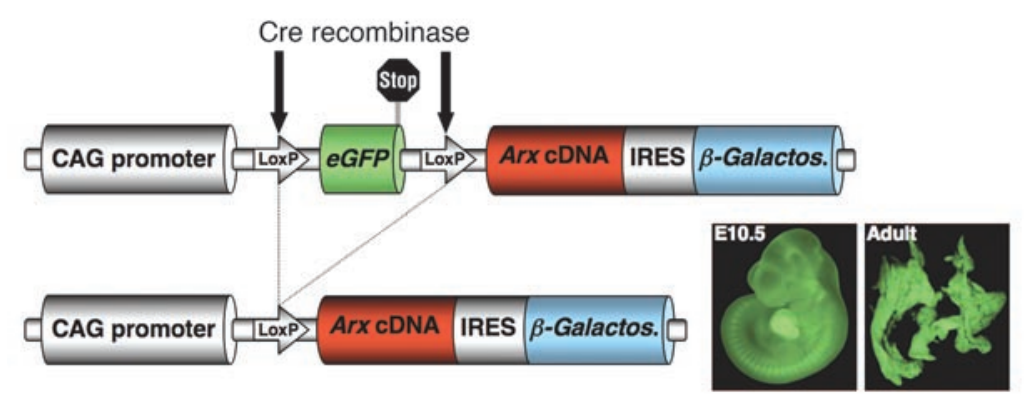

\section{Figure 1}

Generation of animals conditionally misexpressing the Arx gene. Schematic depicting the targeting vector before (top) and after (bottom) recombination of the 2 LoxP sites induced by the phage P1 Cre recombinase. $\beta$-Galactos., $\beta$-galactosidase. Inset: Visual examination of representative Cre-negative E10 embryo and adult pancreas under fluorescent light. Original magnification, $\times 40$. observed in Pax4-deficient mice (25). Furthermore, it was established that, during early stages of endocrine development, a mutual transcriptional inhibition operates between Arx and Pax4 to allocate the different endocrine cell fates (24). These findings suggest that, during early islet cell specification, endocrine progenitor cells exhibit a potential to adopt a $\beta / \delta$ or an $\alpha$ cell fate, the alternative destinies requiring the activities of $\mathrm{Pax} 4$ and Arx, respectively. In the pancreata of $A r x / P a x 4$ double-mutant mice, cells exhibiting all known $\delta$ cell characteristics develop at the expense of $\beta$ and $\alpha$ cells (33), suggesting a secondary requirement of $\operatorname{Pax} 4$ in $\beta / \delta$ cell progenitors for the specification of the $\beta$ cell fate.

To gain further insight into the genetic program underlying the development of the different endocrine subtypes, we used a gainof-function approach to express Arx in the pancreatic epithelium of the pancreas or in islet precursor cells. These mice developed a dramatic hyperglycemia, lacked $\beta$ and $\delta$ cells, and eventually died. Our findings suggest that Arx is both necessary and sufficient to promote endocrine progenitors toward the $\alpha$ and, interestingly, PP cell lineages. We also demonstrate a hitherto unrecognized expression of Arx in PP cells. Most importantly, our data indicate that the ectopic expression of Arx in embryonic or adult insulin-producing $\beta$ cells converts these into cells exhibiting $\alpha$ or PP cell features.

\section{Results}

Generation of transgenic animals conditionally misexpressing Arx. The consequences of Arx and/or Pax4 loss-of-function mutations are consistent with antagonistic roles for Arx and Pax4 in supporting the $\alpha$ cell or the $\beta / \delta$ cell fate, respectively $(24,33)$. To gain further insight into the fate-specifying activities of Arx and Pax4 throughout pancreas morphogenesis, we took advantage of the Cre-LoxP system to generate transgenic mice capable of condition- ally misexpressing the Arx gene (cArxOE mice). The construct used consisted of the CMV enhancer upstream of the human $\beta$-actin promoter (CAG) controlling the constitutive expression of the eGFP gene flanked by LoxP sites (Figure 1, top). The Arx cDNA was cloned downstream of $e$ GFP together with an IRES- $\beta$-galactosidase-encoding sequence. With the use of pronuclear injection, 5 independent transgenic lines were established. In the absence of Cre recombinase activity, we confirmed that only eGFP was constitutively expressed, combining genotyping PCR for the $\beta$-galactosidase gene (data not shown) and fluorescence microscopy (Figure 1 , inset). These animals were subsequently bred with different transgenic mice expressing the phage P1 Cre recombinase enzyme under the control of different gene promoters, including the $P d x 1$ (Pdx1Cre), Pax6 (Pax6Cre), or insulin (InsCre) promoter (17, 34, $35)$. Hence, in the resulting double-transgenic animals, the Cre recombinase, expressed in a time- and space-restricted fashion, was expected to trigger persistent cell-specific Arx expression (Figure 1, bottom). The detection of these double-transgenic mice was performed with a combination of genotyping PCR for the Cre recombinase and $\beta$-galactosidase genes, and fluorescence microscopy.

Arx misexpression in the early pancreas induces a dramatic and lethal byperglycemia associated with the prevalence of glucagon-or PP-expressing cell fates at the expense of the $\beta$ and $\delta$ cell lineages. To address the question of whether Arx function in endocrine progenitors is sufficient to promote the $\alpha$ cell fate, we first induced Arx expression in early pancreatic precursor cells. This was achieved by breeding of cArxOE mice with either Pdx1Cre (to allow an ectopic expression of Arx in the pancreatic endoderm) or Pax6Cre (to allow an ectopic expression of Arx in the endocrine precursors) animals $(17,34)$. Double-transgenic cArxOE::Pdx1Cre and cArxOE::Pax6Cre animals were normally born. However, within 2-6 weeks postpartum,

Table 1

Determination of glucose level in the offspring of cArxOE::Pdx1Cre- or cArxOE::Pax6Cre-crossed animals

\begin{tabular}{|c|c|c|c|c|c|c|c|c|}
\hline \multirow[b]{2}{*}{ Genotype } & \multicolumn{2}{|c|}{ P24h } & \multicolumn{2}{|c|}{3 Weeks } & \multicolumn{2}{|c|}{ SBD } & \multirow{2}{*}{$\begin{array}{c}\text { Pancreas } \\
\text { weight }\end{array}$} & \multirow{2}{*}{$\begin{array}{c}\text { Life } \\
\text { expectancy }\end{array}$} \\
\hline & Urine & Blood & Urine & Blood & Urine & Blood & & \\
\hline WT & $27 \pm 12$ & $90 \pm 12$ & $29 \pm 16$ & $79 \pm 19$ & $38 \pm 22$ & $72 \pm 29$ & $100 \%$ & Normal \\
\hline cArxOE & $35 \pm 18$ & $98 \pm 27$ & $45 \pm 17$ & $92 \pm 17$ & $49 \pm 19$ & $75 \pm 15$ & $100 \%$ & Normal \\
\hline Pdx1Cre & $24 \pm 10$ & $79 \pm 18$ & $36 \pm 25$ & $98 \pm 21$ & $50 \pm 28$ & $88 \pm 31$ & $100 \%$ & Normal \\
\hline Pax6Cre & $33 \pm 12$ & $88 \pm 16$ & $19 \pm 19$ & $76 \pm 29$ & $29 \pm 19$ & $89 \pm 29$ & $100 \%$ & Normal \\
\hline cArx0E::Pdx1Cre & $42 \pm 11$ & $96 \pm 19$ & $92 \pm 28^{A}$ & $408 \pm 159 A$ & $>600^{A}$ & $>600^{A}$ & $60 \% A$ & 2-8 Weeks \\
\hline cArx0E::Pax6Cre & $39 \pm 16$ & $86 \pm 15$ & $120 \pm 58^{A}$ & $388 \pm 122^{A}$ & $>600^{A}$ & $>600^{A}$ & $100 \%$ & 2-12 Weeks \\
\hline
\end{tabular}


cArxOE::Pdx1Cre mice developed growth retardation and pancreatic hypoplasia (Table 1). Both cArxOE::Pdx1Cre and cArxOE:: Pax6Cre mice died approximately 2-12 weeks after birth exhibiting a massive and significant hyperglycemia (Table 1): shortly before death, the blood and urine sugar contents were found drastically increased with values exceeding the maximum detection threshold of our glucose monitoring system ( $>600 \mathrm{mg} / \mathrm{dl}, n=126)$ compared with those of age-matched control animals (urine, $38 \pm 22 \mathrm{mg} / \mathrm{dl}$; blood, $72 \pm 29 ; n=189$ ).

To assess the alterations induced by the misexpression of Arx in $P d x 1$ - or Pax6-expressing progenitors, islets of Langerhans from 6-week-old mice were assayed for the presence of the 4 endocrine cell types by immunohistochemistry (Figure 2). We did not observe any obvious differences between WT and cArxOE pancreata, the latter displaying a uniform GFP labeling (data not shown and Figure 2A). Notably, both cArxOE::Pax6Cre and cArxOE:: $\mathrm{Pdx} 1 \mathrm{Cre}$ islets were found to be negative for GFP and positive for the $\beta$-galactosidase enzyme (Figure $2, \mathrm{~B}$ and $\mathrm{C}$, and insets). In addition, almost all pancreatic cArxOE::Pdx1Cre cells appeared to be GFP-/ $\beta$-galactosidase ${ }^{+}$(Figure $2 \mathrm{C}$ and inset). The examination of both cArxOE::Pax6Cre and cArxOE::Pdx1Cre islets revealed a profound reduction in insulin-producing cell numbers as com-
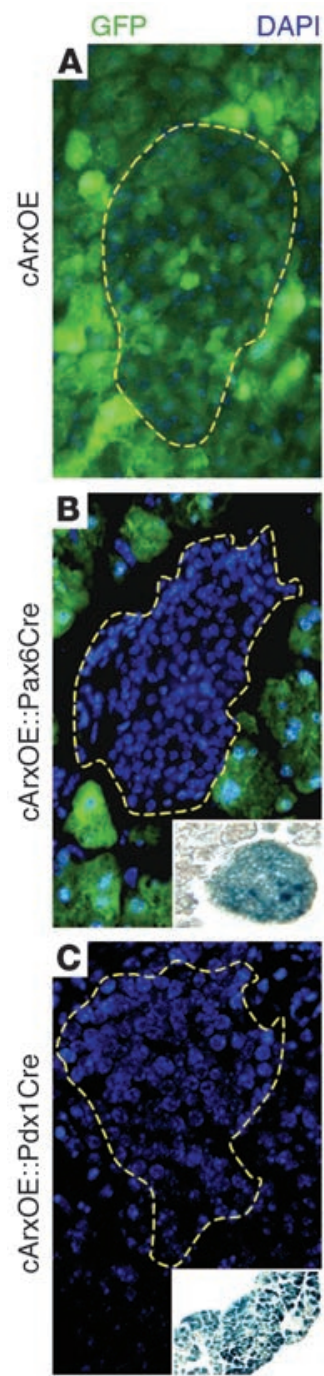
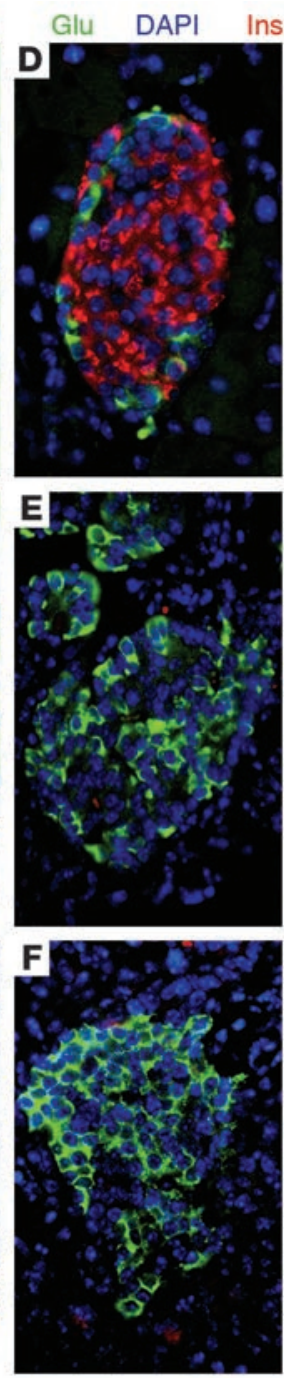
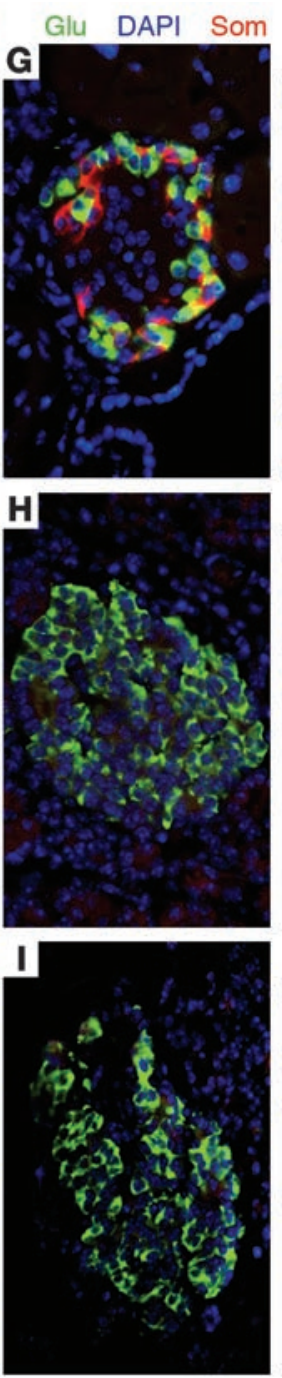
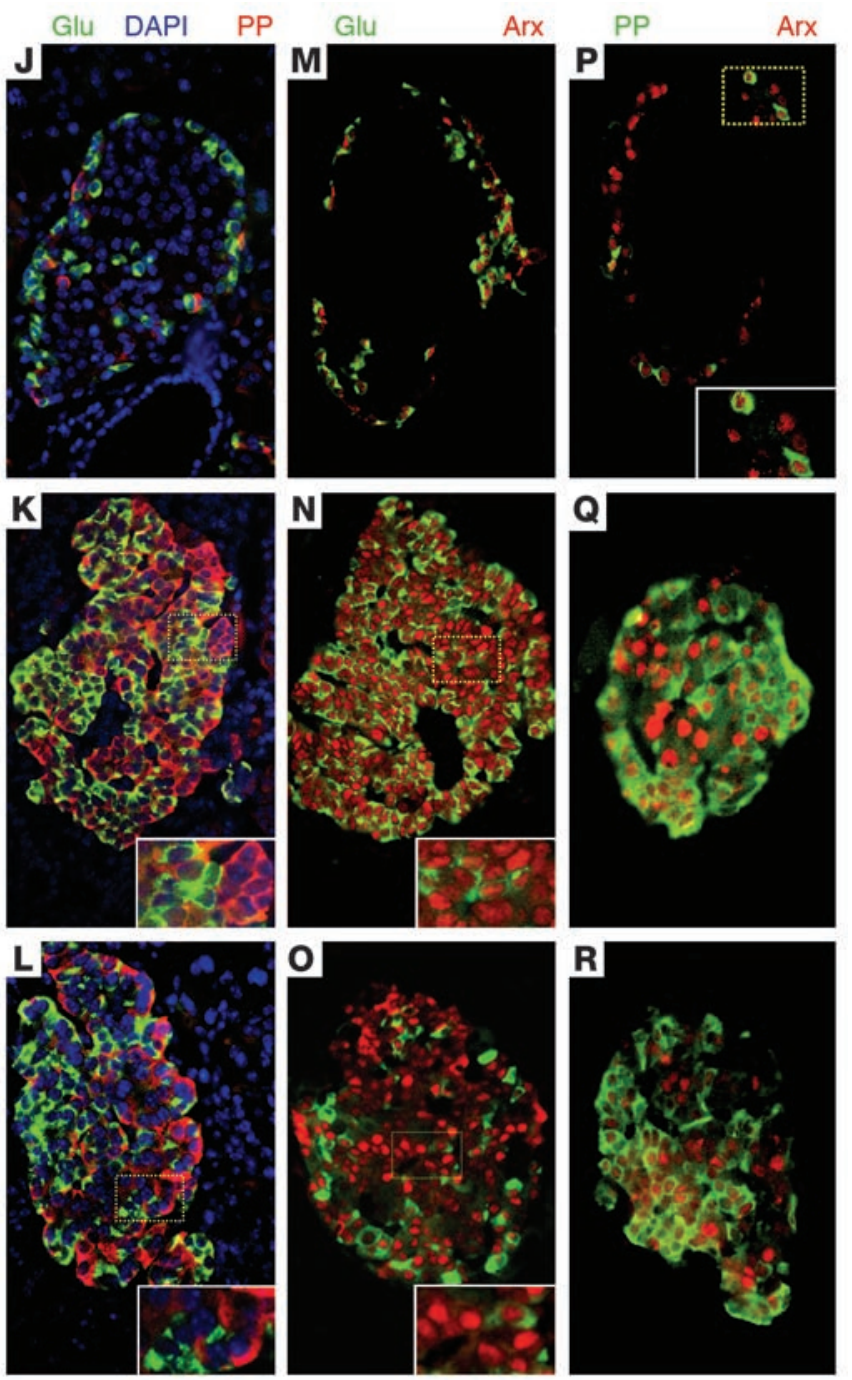

Figure 2

Conditional Arx misexpression restricted to the early pancreas results in a favoring of the glucagon- or PP-producing cell fates at the expense of the $\beta$ and $\delta$ cell lineages. Sections of 6 -week-old mice were examined for the presence of pancreatic hormones in cArxOE (A, D, G, J, M, and P), cArxOE::Pax6Cre (B, E, H, K, N, and Q), and cArxOE::Pdx1Cre (C, F, I, L, O, and R) animals by immunofluorescence. (A-C) The uniform GFP expression found in cArxOE mice (A) is expectedly excluded from the islets in cArxOE::Pax6Cre animals (B) and missing in cArxOE:: Pdx1Cre pancreatic tissue (C). Conversely, the $\beta$-galactosidase activity is clearly detected in cArxOE::Pax6Cre islets (B, inset) and cArxOE:: Pdx1Cre pancreata (C, inset). (D-R) The Cre-mediated misexpression of Arx in Pax6 or Pdx1 expression domains promotes a loss of $\beta$ cell $(\mathbf{D}-\mathbf{F})$ and $\delta$ cell $(\mathbf{G}-\mathbf{I})$ populations, concurrently with an increase in numbers of glucagon-producing (D-O) or PP-producing (J-L) cell numbers. Arx production is uniformly detectable in the endocrine tissue of cArxOE::Pax6Cre and cArxOE::Pdx1Cre mice (M-O). Note that Arx is present in glucagon-labeled cells, and, most likely, in PP-positive cells (insets in $\mathbf{N}$ and $\mathbf{O}$ ). A coexpression of Arx and PP was demonstrated both in controls (P) and in double-transgenic animals ( $Q$ and $\mathbf{R})$. Each picture is representative of 6-15 independent animals. Glu, glucagon; Ins, insulin; Som, somatostatin. Original magnification, $\times 40$. 


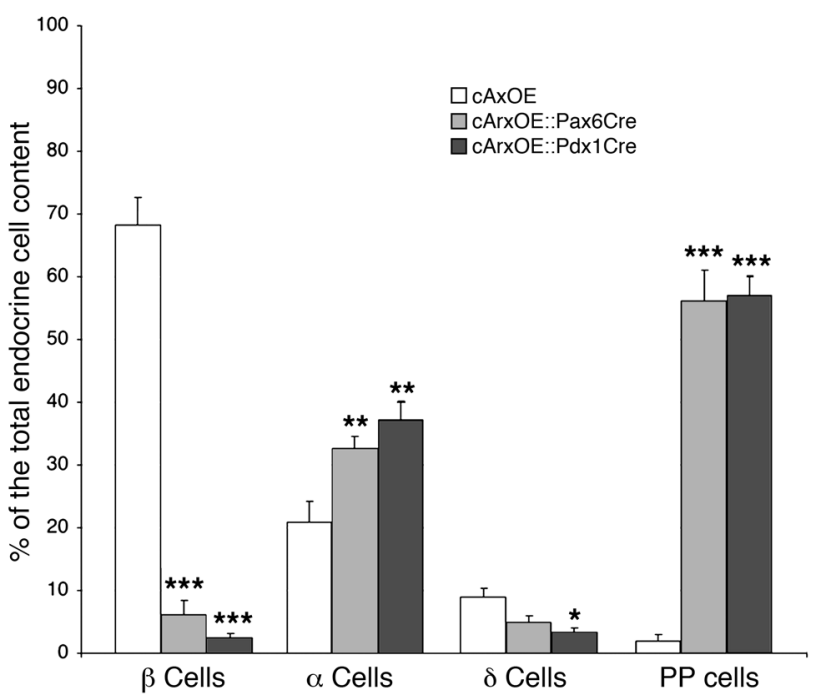

pared with controls (Figure 2, D-F), and only a few scattered somatostatin-expressing cells were detected (Figure 2, G-I). Conversely, a dramatic increase in glucagon-producing cell numbers was observed in these animals (Figure 2, D-O). Interestingly, the number of PP-labeled cells also appeared to be drastically elevated in both genotypes (Figure 2, J-L). Colocalization experiments permitted us to clearly establish that glucagon and PP were never coexpressed (Figure 2, J-L). As expected, in Cre-positive animals, Arx was detected in almost all glucagon-producing cells, but, strikingly, also in numerous cells lacking glucagon (Figure 2, N and $\mathrm{O}$, and insets); this pointed to a labeling of PP cells (since insulin- and somatostatin-marked cells are absent). The codetection of Arx and PP hormones had not been previously attempted for technical reasons. However, using a newly developed guinea pig anti-PP antibody (Linco), we established that Arx is expressed in PP-producing cells, both in control and in double-transgenic animals (Figure 2, P-R). For technical reasons, the expression of Pax4 could not be assessed by means of in situ hybridization, nor immunohistochemistry; however, with the use of a quantitative RT-PCR approach, the pancreatic quantification of Pax4 transcript was found unchanged at that age (data not shown).

To extend our data, a quantitative analysis was performed: independent stage-matched pancreata from cArxOE::Pax6Cre and cArxOE::Pdx1Cre mice were sectioned, and the number of hormone-immunoreactive cells was determined in every tenth section. The results obtained by comparison of the average counts reported with the total endocrine population (Figure 3 and Table 2) confirmed a dramatic loss of insulin-producing cells $(-93 \%$ on average) and a drastic reduction $(-66 \%)$ in the number of somatostatin-expressing cells. In contrast, the mean numbers of

\section{Table 2} misexpression of $A r x$

\section{Figure 3}

Quantification of the phenotypic alterations in hormone-producing cell contents following the targeted misexpression of Arx. Six-week-old independent pancreata estimated to be of the same size were serially sectioned, every tenth section was stained as indicated, and the numbers of positive cells were counted and reported to the total islet cell content (estimated on adjacent sections with the use of a mixture of antibodies raised against the different endocrine hormones). Data are shown as the percentage \pm SEM of hormone-positive cells contributing to the total endocrine population. On average, the misexpression of Arx during early pancreas genesis promotes a dramatic loss of $\beta$ and $\delta$ cells, whereas the contents in glucagon- and PP-labeled cells are proportionally increased. ${ }^{\star} P<0.05,{ }^{* \star} P<0.01$, ${ }^{* \star *} P<0.001 . n \geq 8$.

glucagon- and PP-producing cells were markedly increased in these animals ( $+75 \%$ and $+2,200 \%$, respectively), as compared with control littermates. It is noteworthy that the total endocrine cell content was statistically unchanged in cArxOE::Pax6Cre and cArxOE:: Pdx1Cre pancreata (Table 2) as compared with controls. Interestingly, the exocrine cell mass was found to be significantly decreased in cArxOE::Pdx1Cre mice, suggesting that the forced expression of Arx in $P d x 1$ expression domains might induce a premature differentiation of exocrine precursors. Indeed, a pulse-chase labeling of proliferating cells in the pancreata of these animals, from E12.5 until E16.5, outlined a $17 \%$ decrease in the number of dividing exocrine cells as compared with that in controls, whereas the apoptosis rate appeared to be unchanged. Preliminary results indicated that exocrine cells expressed a normal complement of transcription factors (data not shown). Altogether, our findings suggest that the missing hormone-producing cells in double-transgenic pancreata acquired an alternative endocrine cell fate.

To determine whether these islet alterations were already evident during embryogenesis, endocrine cell genesis was further examined during development and quantified by cell count. In fact, the defects observed were similar to those found postpartum, indicating that the $\beta$ and $\delta$ cell lineages were disfavored in these animals throughout pancreatic endocrine development (Figure 4, A-F and $\mathrm{V}-\mathrm{X})$, being redirected toward the glucagon- or PP-producing cell fates (Figure 4, A-U and Y-DD). The loss of insulin-producing cells was further associated with a dramatic reduction in the expression of the $\beta$ cell-specific factors Nkx6.1, Pdx1, Glut2, Isl1, HB9, and MafA (Figure 4, M-U, Supplemental Figure 1, A-C, and data not shown; supplemental material available online with this article;

Quantification of the phenotypic alterations in hormone-producing cell contents following the targeted

\begin{tabular}{lcccc} 
Genotype & WT & \multicolumn{1}{c}{ CArXOE } & cArxOE::Pax6Cre & cArxOE::Pdx1Cre \\
Endocrine cell count & $809 \pm 72 ; n=26$ & $849 \pm 63 ; n=18$ & $801 \pm 88 ; n=18$ & $782 \pm 99 ; n=17$ \\
Exocrine pancreas size (mm²) & $153 \pm 33 ; n=4$ & $149 \pm 21 ; n=3$ & $126 \pm 36 ; n=4$ & $81 \pm 28 ; n=4^{\mathrm{A}}$ \\
BrdU incorporation (\%) & $100 \pm 2 ; n=3$ & $98 \pm 3 ; n=3$ & $94 \pm 7 ; n=3$ & $82 \pm 6 ; n=3^{\mathrm{A}}$ \\
Apoptosis rate (\%) & $100 \pm 4 ; n=3$ & $100 \pm 5 ; n=3$ & $102 \pm 8 ; n=3$ & $94 \pm 10 ; n=3$ \\
Blood insulin content (\%) & $100 \pm 6 ; n=6$ & $102 \pm 8 ; n=6$ & $26 \pm 13 ; n=3^{\mathrm{A}}$ & $30 \pm 17 ; n=3^{\mathrm{A}}$ \\
Blood glucagon content (\%) & $100 \pm 5 ; n=6$ & $96 \pm 7 ; n=6$ & $116 \pm 6 ; n=3$ & $119 \pm 4 ; n=3$
\end{tabular}

The total endocrine cell content was not statistically modified in any of the genotypes analyzed, whereas the exocrine tissue size and BrdU incorporation are decreased without any change in the number of apoptotic cells. The circulating insulin is also found to be diminished, whereas the blood glucagon levels are found unaltered. Multiple comparisons of the data obtained for each endocrine population in each genotype were processed with a single-factor ANOVA coupled to the Newman-Keuls test using the cArxOE genotype as reference ( ${ }^{A} P<0.05, n \geq 8$ ). 

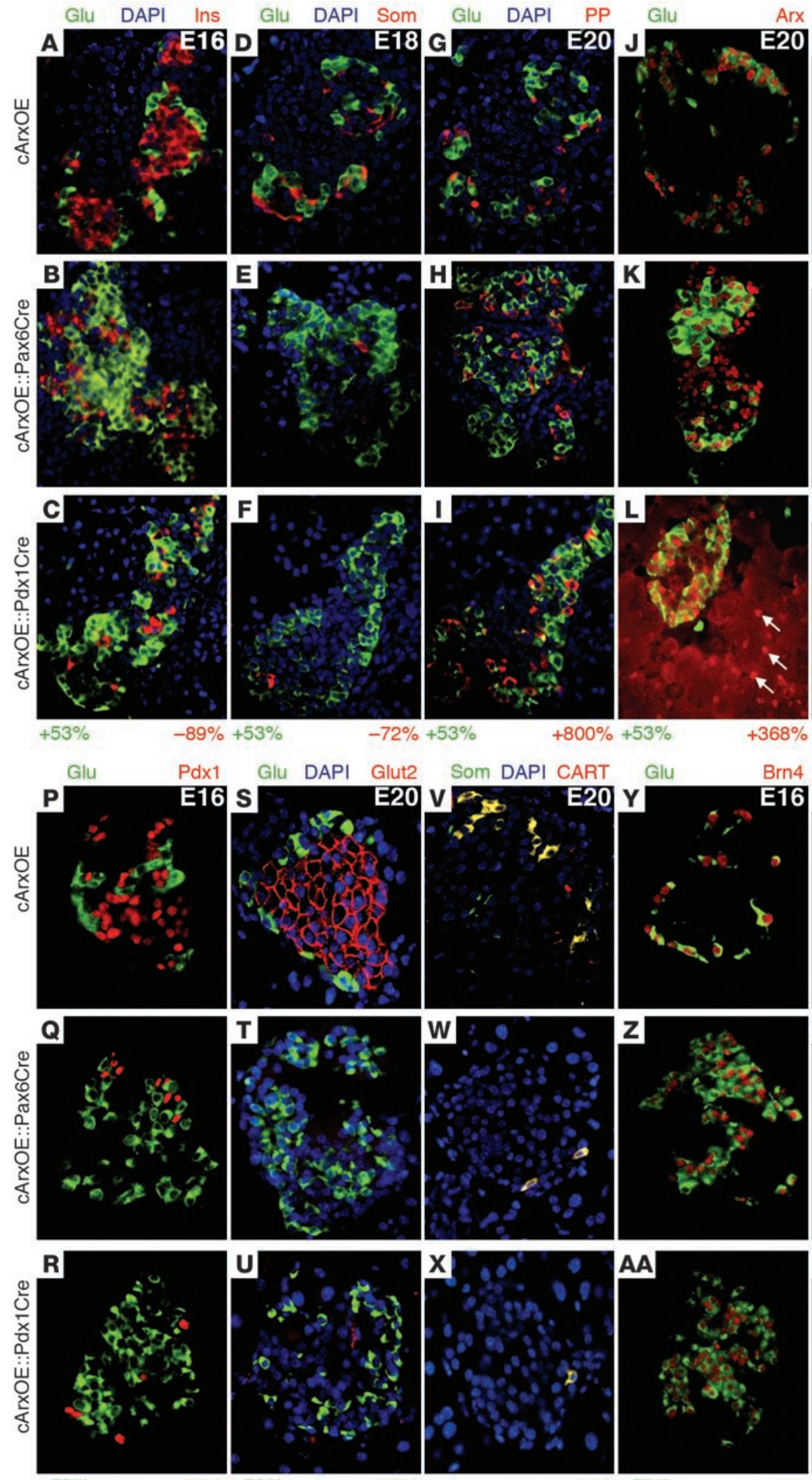

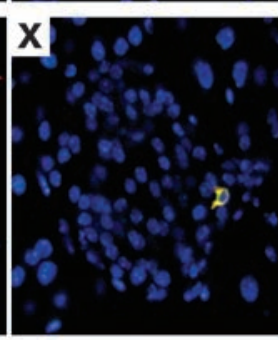

Jis

K

Arx Glu
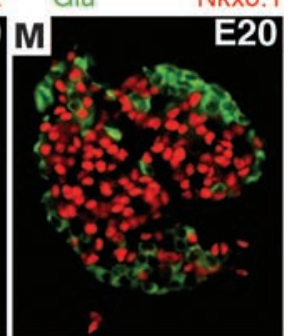

N
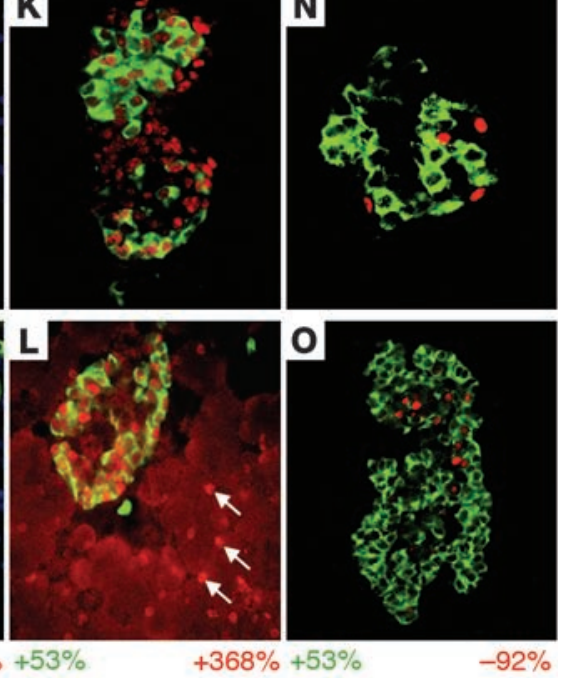

L
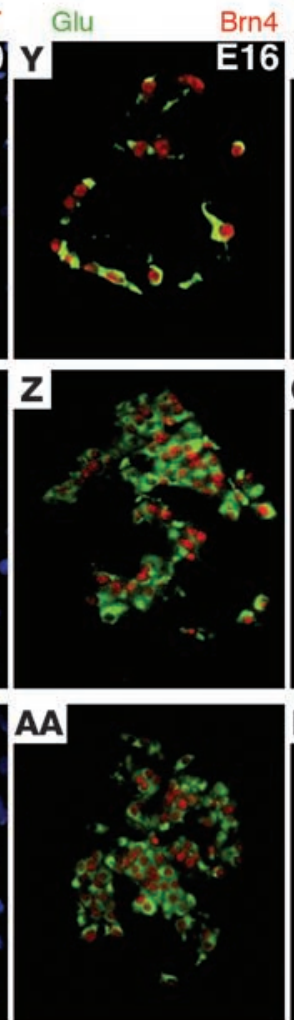

\section{DD}

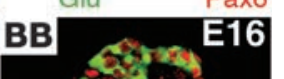

Pax6
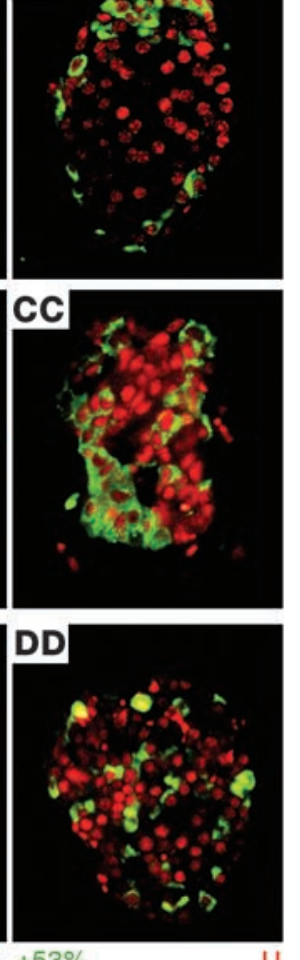

\section{Figure 4}

Favoring of the glucagon- and PP-producing cell fates at the expense of the $\beta$ and $\delta$ cell lineages during endocrine pancreas morphogenesis in cArxOE::Pax6Cre or cArxOE::Pdx1Cre pancreata. (A-DD) Representative pancreatic sections costained with the indicated antibody combinations, at the indicated embryonic stages. A quantification of the endocrine modifications between the Cre-negative and Cre-positive mice, estimated by the 1-tailed Student's $t$ test, is provided in percent under each set of pictures in matching colors $(n \geq 3$, $P<0.05)$. A clear loss of $\beta(\mathbf{A}-\mathbf{C})$ and $\delta(\mathbf{D}-\mathbf{F}$ and $\mathbf{V}-\mathbf{X}$ ) cells is evidenced in animals misexpressing Arx. Concurrently, an increase in glucagon ( $\mathbf{A}-\mathbf{U}$ and Y-DD) or PP (G-I) cell content occurs, with Arx being detected in most of the endocrine tissue $(\mathbf{J}-\mathbf{L})$, but also in exocrine cells in the case of cArXOE::Pdx1Cre (L, arrows). The numbers of cells labeled with the $\beta$ cell-specific markers Nkx6.1 (M-O), Pdx1 (P-R), and Glut2 (S-U) are drastically reduced in Cre-positive mice. Similarly, the expression of CART, normally marking $\delta$ cells, is profoundly diminished $(\mathbf{V}-\mathbf{X})$, whereas the expression of the $\alpha$ cell-specific gene Brn4 is augmented (Y-AA). The content in cells positive for the endocrine marker Pax6 is not affected (BB-DD). Each picture is representative of 3-8 animals from different litters. $U$, unchanged. Original magnification, $\times 40$. 


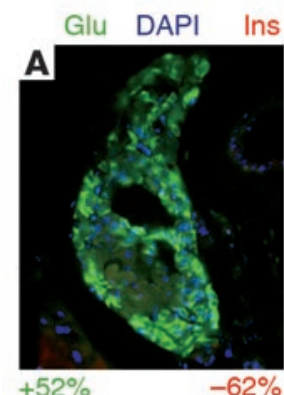

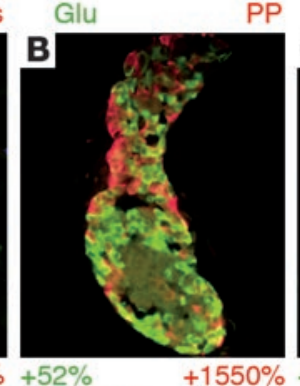

Gilu

P

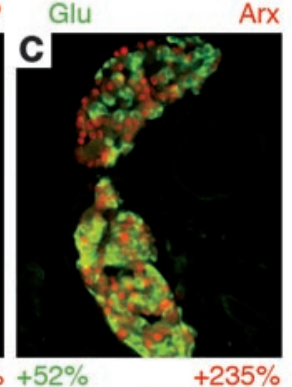

PP

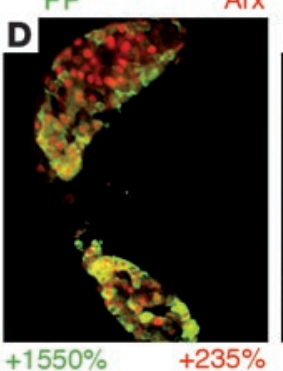

E Glu $+1550 \%+52 \%$ -Gal
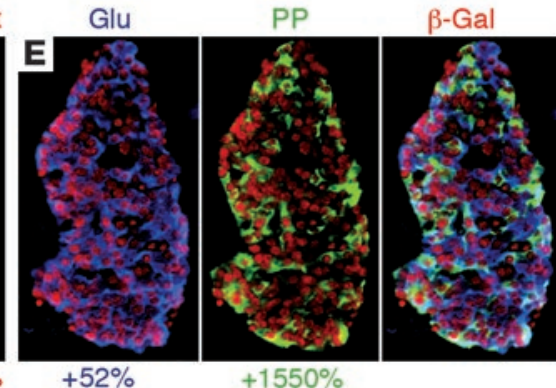

$+1550 \%$

\section{Figure 5}

Arx misexpression converts mature $\beta$ cells into glucagon- or PP-producing cells. (A-D) Representative staining and quantification of the endocrine cell content alterations found in tamoxifen-treated cArxOE:: IndPdx1Cre pancreata with the use of the indicated antibodies. (E) Co-immunohistochemical detection of the glucagon (blue) and PP hormones (green) with the $\beta$-galactosidase enzyme (red). Note that glucagon- or PP-producing cells are positive for the $\beta$-galactosidase. Each picture is representative of $4-7$ animals from different litters. Original magnification, $\times 40$.

doi:10.1172/JCI29115DS1). Similarly, the expression of CART, which exclusively labels $\delta$ cells (36), was found to be decreased (Figure 4, V-X). In contrast, Brn 4 and MafB were detected in most glucagon-producing cells, confirming their normal $\alpha$ cell expression in all genotypes (Figure 4, Y-AA and Supplemental Figure 1, D-F). The PP- or glucagon-producing cells present in cArxOE::Pax6Cre and cArxOE::Pdx1Cre genotypes were positive for Pax6 (Figure 4, BB-DD). By quantitative RT-PCR on E15 whole pancreas, a significant $81 \%$ decrease in Pax4 transcripts was observed in double transgenics $(-77 \% \pm 6 \%$ in cArxOE::Pax6Cre; $-85 \% \pm 8 \%$ in cArxOE:: $\mathrm{Pdx} 1 \mathrm{Cre})$ compared with controls. The islet alterations reported herein were further confirmed by electron microscopy (Supplemental Figure 2 and Supplemental Methods) and blood examination of the endocrine hormone levels (Table 2). Altogether, these results suggest that the ectopic activation of Arx in Pdx1- or Pax6expressing cells prevents endocrine progenitors from adopting a $\beta$ or $\delta$ cell fate through the inhibition of Pax4 expression and instead promotes them toward lineages ultimately resulting in cells exhibiting most features of $\alpha$ or PP cells.

Conversion of $\beta$ cells into cells exhibiting $\alpha$ or PP-producing cell characteristics upon Arx expression in insulin-producing cells. The previously described gain-of-function experiments suggest that the forced expression of Arx in early endocrine progenitors induces their differentiation into $\alpha$ and PP cells at the expense of the $\beta$ and $\delta$ cell lineages. We therefore wondered whether a similar function might also apply to differentiated $\beta$ cells. Hence, 2 different transgenic lines were generated by crossing of cArxOE mice firstly with an InsCre line, and secondly with an inducible Pdx1Cre (IndPdx1Cre) line
(17). In the first case (cArxOE::InsCre), a quantification of islet cells indicated that the forced expression of Arx in cells readily expressing the insulin hormone ultimately resulted in an increase in the content of PP- or glucagon-labeled cells, whereas the $\beta$ cell number was reduced and the $\delta$ cell content remained unchanged (Table 3). Importantly, in the second mating scheme, the induction of the phage P1 Cre recombinase in 4-week-old cArxOE::IndPdx1Cre animals ( $\mathrm{Pdx} 1$ being normally restricted to $\beta$ cells at this age), and the subsequent expression of Arx in $\beta$ cells, promoted a similar phenotype (Table 3). Hence, a loss of insulin-expressing cells and a proportional increase in the numbers of PP- or glucagon-positive cells were observed as early as 1 week after induction (Table 3 and Figure 5, A-D), without any significant change in the total endocrine cell number. In both cases, double-transgenic animals developed a massive hyperglycemia and eventually died. Importantly, $\beta$-galactosidase expression specifically triggered in $\beta$ cells was then detected in a vast majority of glucagon- or PP-producing cells (Figure 5E), those also ectopically producing Arx (Figure 5, C and D), whereas Pax4 expression was found to be unchanged. These results suggest that cells previously expressing $\beta$ cell genetic determinants later activated the glucagon or PP hormones. This was further ascertained through the quantitative analysis of numerous endocrine subtype-specific factors (Table 3). Along the same line, the in vitro misexpression of Arx in the insulin-expressing MIN6 and $\beta$ TC 3 cell lines was found to also induce a conversion of insulin-producing cells into cells producing either glucagon or PP (Supplemental Figure 3). Altogether, it appears that triggering of Arx expression in insulin-expressing cells, in vitro or in vivo, promotes a loss of their molecular characteristics, pointing to a reprogramming of these into cells ultimately presenting features normally associated with $\alpha$ or PP cells.

The misexpression of Arx in mature $\beta$ cells is sufficient to induce alterations in endocrine cell fate. It is important to notice that the phenotypic alterations reported above were similar in the progeny of the 5 different cArxOE lines crossed with the InsCre line. In order to exclude the possibility that the observed endocrine tissue modifications were related to nonphysiological levels of Arx expression, we used real-time RT-PCR to assess Arx production. Hence, Arx expression was found to be variable in the 5 cArxOE::InsCre double-transgenic lines, reflecting the distinct insertion loci of the transgene. Taking into account that in adult mice Arx is normally expressed in $\alpha$ and PP cells, that is, in approximately $23 \%$ of the total endocrine population (Figure 2, controls), one would expect that forcing its expression ectopically in $\beta$ cells (representing approximately $68 \%$ of islet cells) at a physiological level would increase its pancreatic concentration by a factor of approximately $3.95[(23+68) / 23]$. Notably, in 2 of our cArxOE::InsCre transgenic lines, the quantification of the amount of $A r x$ mRNA indicated that this threshold was not reached, with a respective total increase in Arx transcript contents of 2.6 and 3.4 as compared with that in controls (Table 4). Importantly, even in these animals, dramatic alterations in the endocrine cell content could clearly be detected. This suggests that the ectopic expression of Arx in $\beta$ cells at a dose lower than or close to the physiological concentration is sufficient to cell-autonomously trigger a loss of the $\beta$ cell phenotype and induce the glucagon- or PP-expressing cell genetic determinants.

\section{Discussion}

Previous studies have demonstrated that Arx and Pax4 exert mutually antagonistic roles during endocrine pancreas specification 
Table 3

Arx misexpression converts mature $\beta$ cells into glucagon- or PP-producing cells

\begin{tabular}{|c|c|c|c|c|c|c|}
\hline \multirow[t]{2}{*}{ Age } & \multicolumn{2}{|c|}{ E20 } & \multicolumn{2}{|c|}{4 Weeks } & \multicolumn{2}{|c|}{5 Weeks } \\
\hline & cArxOE & cArxOE::InsCre & CArXOE & cArxOE::InsCre & cArxOE & cArxOE::IndPdx1Cre \\
\hline Insulin & $61.6 \%$ & $17.2 \%(-72 \%)$ & $68.6 \%$ & $7.5 \%(-89 \%)$ & $65.1 \%$ & $24.7 \%(-62 \%)$ \\
\hline Glucagon & $26.9 \%$ & $53.5 \%(+99 \%)$ & $21.1 \%$ & $38.3 \%(+81 \%)$ & $23.4 \%$ & $32.8 \%(+52 \%)$ \\
\hline Somatostatin & $10 \%$ & $14.6 \%(U)$ & $8.3 \%$ & $5.9 \%(U)$ & $9.3 \%$ & $7.6 \%(U)$ \\
\hline PP & $1.5 \%$ & $14.7 \%(+880 \%)$ & $2.1 \%$ & $48.3 \%(+2,200 \%)$ & $2.2 \%$ & $36.3 \%(+1,550 \%)$ \\
\hline Arx & $35.1 \%$ & $53.7 \%(+53 \%)$ & $26.7 \%$ & $94 \%(+252 \%)$ & $25.2 \%$ & $84.4 \%(+235 \%)$ \\
\hline Nkx6.1 & $58.2 \%$ & $18.6 \%(-68 \%)$ & $65.2 \%$ & $18.9 \%(-71 \%)$ & $61.1 \%$ & $25.7 \%(-58 \%)$ \\
\hline$P d x 1$ & $63.8 \%$ & $14.7 \%(-77 \%)$ & $71.3 \%$ & $26.4 \%(-63 \%)$ & $59.8 \%$ & $28.1 \%(-53 \%)$ \\
\hline Glut2 & $59.5 \%$ & $10.7 \%(-82 \%)$ & $67 \%$ & $-13.5 \%(-80 \%)$ & $69.4 \%$ & $21.5 \%(-69 \%)$ \\
\hline HB9 & $55.3 \%$ & $22.7 \%(-59 \%)$ & $62.5 \%$ & $28.1 \%(-55 \%)$ & $66.9 \%$ & $26.8 \%(-60 \%)$ \\
\hline Brn4 & $32.2 \%$ & $48 \%(+49 \%)$ & $19.9 \%$ & $34 \%(+71 \%)$ & $21.7 \%$ & $35.2 \%(+62 \%)$ \\
\hline Nkx2.2 & $86.2 \%$ & $91.1 \%(U)$ & $88.4 \%$ & $90.7 \%(U)$ & $91.9 \%$ & $90.8 \%(U)$ \\
\hline$|s| 1$ & $98.6 \%$ & $99.7 \%(U)$ & $98.1 \%$ & $99.3 \%(U)$ & $97.9 \%$ & $95.8 \%(U)$ \\
\hline Pax6 & $99.8 \%$ & $100 \%(U)$ & $99.8 \%$ & $99.6 \%(U)$ & $99.8 \%$ & $99.9 \%(U)$ \\
\hline Cell content & $100 \%$ & $101.5 \%(U)$ & $100 \%$ & $98.7 \%(U)$ & $100 \%$ & $100.4 \%(U)$ \\
\hline Glucose levels & - & - & $89 \mathrm{mg} / \mathrm{dl}$ & $465 \mathrm{mg} / \mathrm{dl}(+422 \%)$ & $105 \mathrm{mg} / \mathrm{dl}$ & $518 \mathrm{mg} / \mathrm{dl}(+393 \%)$ \\
\hline Life expectancy & Normal & 3-6 Weeks & Normal & 3-6 Weeks & Normal & 3-6 Weeks \\
\hline
\end{tabular}

$(24,33)$. Thus, on the basis of loss-of-function phenotypes, it was suggested that Arx is required for the $\alpha$ cell specification of endocrine progenitors, whereas Pax 4 appeared necessary firstly for the $\beta / \delta$ cell fate and later for the $\beta$ cell lineage allocation. These studies clearly established the necessity of Arx and Pax 4 activities for proper islet cell specification. However, they also raised an important question: Are Arx and Pax4 also sufficient to instruct endocrine progenitor cells to adopt an $\alpha$ cell fate or a $\beta(\delta)$ cell lineage, respectively? In order to address this issue, we used a gain-of-function approach and generated transgenic animals conditionally misexpressing Arx.

To assess whether Arx had an instructive role during early pancreas morphogenesis, the expression of this factor was induced firstly in the early pancreas. Hence, mice misexpressing Arx in $P d x 1$ or Pax 6 expression domains developed a pronounced hyperglycemia as a result of hypoinsulinemia and eventually died. By electron microscopy and immunohistochemistry, a dramatic decrease in the numbers of $\beta$ and $\delta$ cells was highlighted, concurrently with a proportional augmentation in the numbers of glucagonor PP-producing cells. A pancreatic hypoplasia was also detected in cArxOE::Pdx1Cre mice. Importantly, the total endocrine cell number was found to be unchanged as compared with that in controls, albeit a decrease in exocrine cell number without identity alteration was observed in cArxOE::Pdx1Cre mice (P. Collombat, unpublished observations). The expression of Arx in $\alpha$ and PP cells and the favoring of both cell lineages upon Arx misexpression in cArxOE::Pdx1Cre or cArxOE::Pax6Cre islets suggest that $\alpha$ and PP cells may share a common progenitor. However, this is in contradiction with previous experiments supporting the notion that PP expression may be a hallmark of the $\beta$ cell lineage: PP cell ablation resulted in a concomitant loss of $\beta$ and $\delta$ cells (37), and cell lineage tracing revealed that a PPCre transgene also labeled $\beta$ cells (35). The latter may also be consistent with a low expression of PP in early $\beta / \delta$ precursor cells. The discrimination between these 2 possibilities will require additional experiments, e.g., Cre-LoxP recombination-based lineage-tracing analysis using an ArxCre line.

To verify whether the induction of Arx expression in $\beta$ cells would endow them with $\alpha$ or PP cell properties, Arx was ectopically expressed in mature insulin-producing cells as soon as these initiated hormone production during embryogenesis, or in adult $\beta$ cells. In both instances, a lethal hyperglycemia was observed concurrently with a dramatic reduction in the $\beta$ cell content and a proportional increase in the glucagon- or PP-producing cell numbers, whereas the $\delta$ cell population was unchanged. Further analysis of cArxOE::InsCre and tamoxifen-treated cArxOE::IndPdx1Cre animals combining quantitative real-time PCR and lineage-tracing experiments established that (a) the overall Arx transcript content in $\beta$ cells of such mice does not exceed the level of Arx mRNA normally detected in $\alpha$ or PP cells; (b) the specific and permanent $\beta$-galactosidase labeling of $\beta$ cells becomes restricted to $\alpha$ and PP cells upon tamoxifen induction; and (c) the total endocrine cell content remains statistically unchanged (data not shown). It is also important to notice that the phage P1 Cre recombinase in InsCre mice is expressed in more than $90 \%$ of insulin-producing cells (ref. 33; P. Collombat, unpublished observations). In a similar fashion, the forced expression of Arx in vitro was found to induce the conversion of MIN6 and $\beta$ TC 3 insulin-producing cells into glucagon- or PP-expressing cells.

Thus, our data support the notion that Arx is able to drive endocrine progenitors toward an $\alpha$ or PP cell fate or induce the conversion of insulin-producing cells into $\alpha$ or PP cells. These 2 functions should be clearly defined. In the first case, an obvious downregulation of Pax4 transcription was highlighted. This is in agreement with previous data demonstrating that, in the absence of Pax4, Arx prevails in endocrine precursors and prevents them from adopting a $\beta / \delta$ cell fate. In the second case, Arx was also found capable of 


\section{Table 4}

Quantification of transcript contents in 4-week-old cArxOE::InsCre pancreas

\begin{tabular}{|c|c|c|c|c|c|c|}
\hline & cArxOE & cArxOE::InsCre & cArxOE::InsCre & cArx0E::InsCre & cArxOE::InsCre & cArxOE::InsCre \\
\hline & Lines $1-5$ & Line 1 & Line 2 & Line 3 & Line 4 & Line 5 \\
\hline Insulin & $100 \%$ & $-91 \%$ & $-88 \%$ & $-90 \%$ & $-77 \%$ & $-93 \%$ \\
\hline Glucagon & $100 \%$ & $+72 \%$ & $+36 \%$ & $+81 \%$ & $+69 \%$ & $+63 \%$ \\
\hline Somatostatin & $100 \%$ & U & U & U & U & U \\
\hline PP & $100 \%$ & $+1,682 \%$ & $+1,964 \%$ & $+2,002 \%$ & $+4,200 \%$ & $+1,812 \%$ \\
\hline Arx & $100 \%$ & $+416 \%$ & $+567 \%$ & $+259 \%$ & $+908 \%$ & $+341 \%$ \\
\hline
\end{tabular}

The misexpression of Arx is sufficient to trigger dramatic alterations in the endocrine cell fate allocation processes. The 5 different cArxOE transgenic lines reported in this study were crossed with InsCre mice, and the expression levels for the indicated genes were measured by a quantitative RT-PCR approach. Note that the hormone expression level alterations are consistent with the notion that Arx induces the glucagon and PP cell fates at the expense of the $\beta$ cell lineages in 4-week-old cArxOE::InsCre pancreas. Importantly, in lines 3 and 5 , Arx expression remains below the expected physiological dosage (in boldface). All reported values are statistically significant by 1 -tailed Student's $t$ test $(P<0.05, n=3)$ and were further confirmed by immunohistochemistry (data not shown).

cell-autonomously overriding the $\beta$ cell phenotype in adult mice or in vitro and promoting the $\alpha$ and PP cell identity. This was achieved without any detectable modification of Pax4 expression. However, at this age, Pax4 expression is either lacking or very low. Hence, from our analysis, we can conclude that Arx function is not only to drive endocrine precursors away from the $\beta / \delta$ cell fate, but also to participate actively in the acquisition of the $\alpha$ or PP cell identity. Additionally, we demonstrate that differentiated $\beta$ cells retain the potential to become other islet cell subtypes.

The fact that Arx misexpression induces either the $\alpha$ or the PP cell lineage is intriguing and raises several questions: (a) What are the mechanisms underlying the selection of either fate? (b) Why did we not observe any cells positive for both glucagon and PP hormones? (c) Why did endocrine cells become $\alpha$ and not PP cells in the absence of Pax4? (d) Similarly, why did the PP cell number appear to be unchanged in Arx mutants? Concerning the differential specification toward either the $\alpha$ or the PP cell fate (questions $\mathrm{a}$ and $\mathrm{b}$ ), a logical explanation would be that both fates exclude each other. This could be easily achieved by a mutual inhibition of 2 transcription factors - as occurs with Arx and Pax 4 at early developmental stages - with one factor promoting the $\alpha$ cell fate, and the other the PP cell lineage; whether Arx is one of them is unclear. Alternatively, the selective presence of a cofactor, differential posttranslational modifications of Arx, an unsuspected function of Pax4, a developmental stage-dependent role of Arx, and/or different Arx protein thresholds could explain the favoring of one lineage over the other. It is clear that further work is required to discriminate between these possibilities: a yeast 2-hybrid screen to uncover potential Arx-binding partners and a clustered analysis of the transcriptome of the different loss- and gain-of-function lines in our hands are ongoing and should allow further insight into the mechanisms involved.

As for the differences in PP cell contents between the loss-of-function and gain-of-function animals (questions $\mathrm{c}$ and $\mathrm{d}$ ): The misexpression of Arx in the endocrine tissue clearly demonstrates its involvement in PP cell genesis. However, the molecular mechanisms linking Arx to the PP cell lineage are still unclear. In fact, in the endocrine tissue of Arx and/or Pax4 mutants, the PP cell content was not found to be statistically modified. One should underline that this analysis was strongly complicated by the small number of PP cells in a normal islet: it could well be that the modifications in PP cell contents following Arx or Pax 4 depletion cannot be statistically ascertained without a major increase in the number of sam- ples. Interestingly, with the use of a microarray approach coupled to quantitative RT-PCR, an approximately 1.9-fold decrease in PP transcripts or PP cell-associated marker mRNA was evidenced in Arx mutants (P. Collombat, unpublished observations), indicating that Arx deletion may in fact induce a decrease in the PP cell number. However, the magnitude of the modifications of the PP cell content, if this is true, would be much reduced as compared with those in double-transgenic animals. Furthermore, adding to the complexity of the model, the endocrine cell ablation experiments mentioned previously have revealed that the loss of PP cells might be associated with a loss of $\beta$ and $\delta$ cells. This finding may suggest that in addition to the involvement of Arx, PP cell genesis may be related to $\beta$ and $\delta$ cell genesis. It is therefore clear that a full understanding of the molecular mechanisms underlying PP cell genesis will require a tour de force involving multiple approaches, such as (a) the characterization of the putative partners and targets of Arx, but also of Pax4; (b) the determination of potential posttranslational modifications of both factors during pancreas morphogenesis; (c) the characterization of Pax4 expression during late embryogenesis and throughout adulthood; and (d) the combined lineage-tracing analysis of Arx-, Pax4-, and PP-expressing cells in WT, loss-of-function, and gain-of-function genotypes.

Our study demonstrates that the misexpression of Arx is able to cell-autonomously convert differentiated $\beta$ cells into cells displaying $\alpha$ and PP cell characteristics, but it also points to the existence of a plasticity of differentiated $\beta$ cells. In this respect, several studies previously suggested that a particular endocrine cell fate might be reversible. Indeed, Wang et al. (38) have demonstrated in vitro that the overexpression of a dominant-negative form of $\mathrm{Pdx} 1$ in INS- 1 cells induces a dramatic reduction in $\beta$ cell-specific markers and a concomitant increase in $\alpha$ cell determinants. Similarly, following the deletion of the $P d x 1$ gene in $\beta$ cells, a diminution in the $\beta$ cell content was evidenced concurrently with an augmentation in the number of $\alpha$ cells (14). Most interesting was the observation of numerous cells expressing both insulin and glucagon, suggesting a transitional state during the conversion of $\beta$ into $\alpha$ cell phenotypes. Although Arx expression was not assayed in such studies, the similarity between these and the present findings suggests that common mechanisms leading to a phenotype conversion might be involved.

In conclusion, our analysis demonstrates that Arx is both necessary and sufficient to instruct endocrine progenitor cells to adopt a glucagon-producing cell identity at the expense of the 
$\beta$ and $\delta$ cell lineages. Furthermore, Arx appears to have an unsuspected role in promoting the PP-producing cell fate. Importantly, when ectopically expressed in mature adult $\beta$ cells, Arx is able to respecify the $\beta$ cell phenotype and bestow these cells with $\alpha$ or PP cell properties. In light of the antagonistic interaction between Arx and Pax 4 activities during the specification of the endocrine pancreas, it is conceivable that the misexpression of Pax4 and/or the inhibition of Arx might promote the exclusive specification of endocrine progenitors toward the $\beta$ cell lineage and/or convert endocrine cells into $\beta$ cells, thereby opening interesting perspectives for therapeutic purpose.

\section{Methods}

Generation of transgenic animals. The strategy used to generate the cArxOE mouse line is depicted in Figure 1. Transgenic animals were further bred with Pdx1Cre, Pax6Cre, or InsCre mice $(17,34,35)$ and genotyped by a combination of fluorescence microscopy for GFP examination and genotyping PCR for the Cre and $\beta$-galactosidase genes. In a second breeding scheme, cArxOE mice were crossed with an inducible Pdx1Cre line. The tamoxifen induction was performed as described previously (39) in 4-week-old animals that were examined a week later. Animal care and experimental use were approved by the Nidersäxhsisches Landesamt für Verbraucherschutz und Lebensmittelsicherheit board, Oldenburg, Germany.

Immunohistochemistry. Tissues were fixed in $4 \%$ paraformaldehyde overnight at $4{ }^{\circ} \mathrm{C}$ and embedded in paraffin, and $6-\mu \mathrm{m}$ sections were applied to slides. These sections were assayed as described previously (24). In order to perform codetection experiments, the GFP signal found in transgenic animals was eliminated through an extended time of incubation in warm paraffin (up to 2 days) and pressure-boiling of the sections in unmasking solution (Vector Laboratories) according to the manufacturer's instructions. Immunohistochemical assessment of $\beta$-galactosidase expression was performed with the VECTASTAIN ABC kit (Vector Laboratories) with diaminobenzidine tetrahydrochloride as a substrate. The primary antibodies used were the following: mouse monoclonal anti-insulin, anti-glucagon (1:1,000; Sigma-Aldrich), anti-Ngn3 (1:500), and anti- $\beta$-galactosidase (1:1,000; Promega); guinea pig anti-insulin, anti-glucagon (1:1,000; SigmaAldrich), and anti-PP (1:200); and rabbit anti-somatostatin (1:600; Dako), anti-PP (1:200; Dako), anti-Glut2 (1:500; Chemicon), anti-Pdx1 (1:500; Chemicon), anti-Brn4 (1:1,000; Chemicon), anti-Nkx6.1 (1:3,000), antiNkx2.2 (1:1,000; kindly provided by T. Jessell, Columbia University, New York, New York, USA), anti-Brn4 (1:2,000; kindly provided by G. Rosenfeld, Howard Hughes Medical Institute, La Jolla, California, USA), anti-Pax6 (1:500; kindly provided by S. Saule, CNRS UMR 146, Orsay, France), anti$\operatorname{Arx}(1: 1,000)$, anti-CART $(1: 1,000)$, anti-MafA $(1: 1,500$; kindly provided by I. Artner, Vanderbilt University Medical Center, Nashville, Tennessee, USA), and anti-MafB (1:500; kindly provided by I. Artner). The secondary antibodies used (1:1,000; Invitrogen) were 594 Alexa anti-mouse, 488 Alexa antimouse, 594 Alexa anti-rabbit, 488 Alexa anti-rabbit, 594 Alexa anti-guinea pig, and 488 Alexa anti-guinea pig. The stained sections were analyzed by confocal microscopy (Olympus).

Glucose, insulin, and glucagon level determinations. Glucose levels (mg/dl) were determined with the OneTouch Glucose monitoring kit (Johnson \& Johnson) with $15 \mu \mathrm{l}$ of peripheral blood. Blood glucose levels are represented as an average \pm SEM (in certain cases, glucose levels exceeded the $600 \mathrm{mg} / \mathrm{dl}$ detection threshold of the apparatus; this later value was then used for statistical purposes). Insulin and glucagon levels were quantified with the use of RIA (Linco) according to the manufacturer's instructions.

$\beta$-Galactosidase staining. Pancreatic tissues were isolated and fixed in $4 \%$ paraformaldehyde overnight. Next, the embryos and tissues were washed in PBS and then incubated in staining solution $(4 \mathrm{mM} \mathrm{K} 3[\mathrm{Fe}(\mathrm{CN})] 6), 4 \mathrm{mM}$ $\mathrm{K} 4[\mathrm{Fe}(\mathrm{CN}) 6], 0.02 \% \mathrm{NP}-40,0.01 \%$ Na-deoxycholate, $5 \mathrm{mM}$ EGTA, $2 \mathrm{mM}$ $\mathrm{MgCl}_{2}$, and $0.4 \mathrm{mg} / \mathrm{ml}$ 5-bromo-4-chloro-3-inodolyl-D-galactopyranoside. Before sectioning, tissues were dehydrated through ethanol series, cleared in toluene, and embedded in paraffin for further sectioning.

Transfection of insulin-producing cell lines. To allow a constitutive expression of Arx, MIN6 and $\beta$ TC 3 insulin-producing cell lines were transfected (Lipofectamine; Invitrogen) with the construct displayed in Figure 1 (top) after removal of the GFP cassette in Cre-expressing bacteria. The original construction (expressing GFP) was used as transfection control. Data were collected 48 hours after transfection.

Quantitative RT-PCR analysis. RNA isolation, cDNA synthesis, and RTPCR were carried out with the QuantiTect SYBR Green RT-PCR kit (QIAGEN) and validated primers (QIAGEN; Supplemental Table 1) according to the manufacturer's instructions. The PCR reactions and detection were performed on a Mastercycler ep realplex cycler with the use of GAPDH and HPRT1 as internal controls for normalization purposes.

Statistics. The different methods used for data comparisons are described in the text and legends. Briefly, single factor ANOVA coupled to NewmanKeuls test was used for multiple population comparison, whereas a 1-tailed Student's $t$ test was applied to compare populations with single variance. $P$ values lower than or equal to 0.05 were considered significant.

\section{Acknowledgments}

We are most grateful to G. Gradwohl, G. Mellitzer, and M. Diaconu for discussion and to Pascal Dowling for careful reading of the manuscript. We also thank T. Mündiger, R. Faubel, U. Franke, and S. Schrötter for excellent technical assistance, as well as U. Teichman and our animal facility crew for their support with the mice. We are indebted to T. Jessell, I. Artner, and S. Saule for providing reagents and to D.A. Melton for supplying us with mice. This work was supported by the Max Planck Society (A. Mansouri and P. Collombat), Dr. H. Storz and Alte Leipziger foundation (A. Mansouri), the Swiss National Science Foundation (P.L. Herrera), the JDRF (Juvenile Diabetes Research Foundation) Center for Beta Cell Therapy in Europe (P. Serup and P.L. Herrera), and the NIH Beta Cell Biology Consortium (grant U19 DK072495-01; P. Collombat, J. Hecksher-Sørensen, P.L. Herrera, P. Serup, and A. Mansouri).

Received for publication May 17, 2006, and accepted in revised form January 2, 2007.

Address correspondence to: Patrick Collombat or Ahmed Mansouri, Max Planck Institute for Biophysical Chemistry, Department of Molecular Cell Biology, Am Fassberg, D-37077 Göttingen, Germany. Phone: 49-551-2011709; Fax: 49-551-2011504; E-mail: pcollom@gwdg.de (P. Collombat); amansou@gwdg.de (A. Mansouri). Or to: Palle Serup, Hagedorn Research Institute, Department of Developmental Biology, Niels Steensensvej 6, DK-2820 Gentofte, Denmark. Phone: 45-4443-9822; Fax: 45-4443-8000; E-mail: pas@hagedorn.dk.
1. Adrian, T.E., Bloom, S.R., Hermansen, K., and Ivers-
en, J. 1978. Pancreatic polypeptide, glucagon and
insulin secretion from the isolated perfused canine
pancreas. Diabetologia. 14:413-417.
2. Csaba, Z., and Dournaud, P. 2001. Cellular biology

of somatostatin receptors. Neuropeptides. 35:1-23. 3. Roncoroni, L., Violi, V., Montanari, M., and Muri, M. 1983. Effect of somatostatin on exocrine pancreas evaluated on a total external pancreatic fistula of neoplastic origin. Am. J. Gastroenterol. 78:425-428.
4. Heller, R.S., et al. 2005. Genetic determinants of pancreatic epsilon-cell development. Dev. Biol. 286:217-224.

5. Wierup, N., Svensson, H., Mulder, H., and Sundler, F. 2002. The ghrelin cell: a novel developmentally 
regulated islet cell in the human pancreas. Regul. Pept. 107:63-69.

6. Edlund, H. 2002. Pancreatic organogenesis: developmental mechanisms and implications for therapy. Nat. Rev. Genet. 3:524-532.

7. Herrera, P.L., et al. 1991. Embryogenesis of the murine endocrine pancreas: early expression of pancreatic polypeptide gene. Development. 113:1257-1265.

8. Teitelman, G., Alpert, S., Polak, J.M., Martinez, A., and Hanahan, D. 1993. Precursor cells of mouse endocrine pancreas coexpress insulin, glucagon and the neuronal proteins tyrosine hydroxylase and neuropeptide Y, but not pancreatic polypeptide. Development. 118:1031-1039.

9. Upchurch, B.H., Aponte, G.W., and Leiter, A.B. 1994. Expression of peptide YY in all four islet cell types in the developing mouse pancreas suggests a common peptide YY-producing progenitor. Development. 120:245-252.

10. Pictet, R.L., Clark, W.R., Williams, R.H., and Rutter, W.J. 1972. An ultrastructural analysis of the developing embryonic pancreas. Dev. Biol. 29:436-467.

11. Jonsson, J., Carlsson, L., Edlund, T., and Edlund, H. 1994. Insulin-promoter-factor 1 is required for pancreas development in mice. Nature. 371:606-609.

12. Ahlgren, U., Jonsson, J., and Edlund, H. 1996. The morphogenesis of the pancreatic mesenchyme is uncoupled from that of the pancreatic epithelium in IPF1/PDX1-deficient mice. Development. 122:1409-1416.

13. Offield, M.F., et al. 1996. PDX-1 is required for pancreatic outgrowth and differentiation of the rostral duodenum. Development. 122:983-995.

14. Ahlgren, U., Jonsson, J., Jonsson, L., Simu, K., and Edlund, H. 1998. $\beta$-Cell-specific inactivation of the mouse Ipf1/Pdx 1 gene results in loss of the $\beta$-cell phenotype and maturity onset diabetes. Genes Dev. 12:1763-1768.

15. Grapin-Botton, A., Majithia, A.R., and Melton, D.A 2001. Key events of pancreas formation are triggered in gut endoderm by ectopic expression of pancreatic regulatory genes. Genes Dev. 15:444-454.

16. Apelqvist, A., et al. 1999. Notch signalling controls pancreatic cell differentiation. Nature. 400:877-881.

17. Gu, G., Dubauskaite, J., and Melton, D.A. 2002.
Direct evidence for the pancreatic lineage: NGN3+ cells are islet progenitors and are distinct from duct progenitors. Development. 129:2447-2457.

18. Jensen, J., et al. 2000. Independent development of pancreatic alpha- and beta-cells from neurogenin3expressing precursors: a role for the notch pathway in repression of premature differentiation. Diabetes. 49:163-176.

19. Schwitzgebel, V.M., et al. 2000. Expression of neurogenin 3 reveals an islet cell precursor population in the pancreas. Development. 127:3533-3542.

20. Sommer, L., Ma, Q., and Anderson, D.J. 1996. neurogenins, a novel family of atonal-related bHLH transcription factors, are putative mammalian neuronal determination genes that reveal progenitor cell heterogeneity in the developing CNS and PNS. Mol. Cell. Neurosci. 8:221-241.

21. Gradwohl, G., Dierich, A., LeMeur, M., and Guillemot, F. 2000. neurogenin 3 is required for the development of the four endocrine cell lineages of the pancreas. Proc. Natl. Acad. Sci. U. S. A. 97:1607-1611.

22. Sussel, L., et al. 1998. Mice lacking the homeodomain transcription factor $\mathrm{Nkx} 2.2$ have diabetes due to arrested differentiation of pancreatic beta cells. Development. 125:2213-2221.

23. Sander, M., et al. 2000. Homeobox gene Nkx6.1 lies downstream of $\mathrm{Nkx} 2.2$ in the major pathway of beta-cell formation in the pancreas. Development. 127:5533-5540.

24. Collombat, P., et al. 2003. Opposing actions of Arx and Pax4 in endocrine pancreas development. Genes Dev. 17:2591-2603.

25. Sosa-Pineda, B., Chowdhury, K., Torres, M., Oliver, G., and Gruss, P. 1997. The Pax4 gene is essential for differentiation of insulin-producing beta cells in the mammalian pancreas. Nature. 386:399-402.

26. Smith, S.B., Ee, H.C., Conners, J.R., and German, M.S 1999. Paired-homeodomain transcription factor PAX4 acts as a transcriptional repressor in early pancreatic development. Mol. Cell. Biol. 19:8272-8280.

27. Ahlgren, U., Pfaff, S.L., Jessell, T.M., Edlund, T. and Edlund, H. 1997. Independent requirement for ISL1 in formation of pancreatic mesenchyme and islet cells. Nature. 385:257-260.

28. Artner, I., et al. 2006. MafB: an activator of the glu- cagon gene expressed in developing islet alpha- and beta-cells. Diabetes. 55:297-304.

29. Sander, M., et al. 1997. Genetic analysis reveals that PAX6 is required for normal transcription of pancreatic hormone genes and islet development. Genes Dev. 11:1662-1673.

30. St-Onge, L., Sosa-Pineda, B., Chowdhury, K., Mansouri, A., and Gruss, P. 1997. Pax6 is required for differentiation of glucagon-producing alpha-cells in mouse pancreas. Nature. 387:406-409.

31. Guz, Y., et al. 1995. Expression of murine STF-1, a putative insulin gene transcription factor, in beta cells of pancreas, duodenal epithelium and pancreatic exocrine and endocrine progenitors during ontogeny. Development. 121:11-18.

32. Matsuoka, T.A., et al. 2004. The MafA transcription factor appears to be responsible for tissue-specific expression of insulin. Proc. Natl. Acad. Sci. U. S. A. 101:2930-2933

33. Collombat, P., et al. 2005. The simultaneous loss of Arx and Pax4 genes promotes a somatostatinproducing cell fate specification at the expense of the alpha- and beta-cell lineages in the mouse endocrine pancreas. Development. 132:2969-2980.

34. Ashery-Padan, R., et al. 2004. Conditional inactivation of Pax6 in the pancreas causes early onset of diabetes. Dev. Biol. 269:479-488.

35. Herrera, P.L. 2000. Adult insulin- and glucagonproducing cells differentiate from two independent cell lineages. Development. 127:2317-2322.

36. Jensen, P.B., et al. 1999. The hypothalamic satiety peptide CART is expressed in anorectic and nonanorectic pancreatic islet tumors and in the normal islet of Langerhans. FEBS Lett. 447:139-143.

37. Herrera, P.L., et al. 1994. Ablation of islet endocrine cells by targeted expression of hormone-promoter-driven toxigenes. Proc. Natl. Acad. Sci. U. S. A. 91:12999-13003.

38. Wang, H., et al. 2001. Pdx1 level defines pancreatic gene expression pattern and cell lineage differentiation. J. Biol. Chem. 276:25279-25286.

39. Zhang, H., Fujitani, Y., Wright, C.V., and Gannon, M. 2005. Efficient recombination in pancreatic islets by a tamoxifen-inducible Cre-recombinase. Genesis. 42:210-217. 